\title{
Development and Characterization of Photoinduced Acrylamide-Grafted Polylactide Films for Biomedical Applications
}

\author{
Mijanur Rahman, Paiboon Sreearunothai, and Pakorn Opaprakasit \\ School of Biochemical Engineering and Technology, Sirindhorn International Institute of Technology (SIIT), Thammasat University, \\ Pathum Thani 12121, Thailand
}

Correspondence should be addressed to Pakorn Opaprakasit; pakorn@siit.tu.ac.th

Received 24 May 2017; Revised 18 July 2017; Accepted 8 August 2017; Published 12 December 2017

Academic Editor: Cornelia Vasile

Copyright (C) 2017 Mijanur Rahman et al. This is an open access article distributed under the Creative Commons Attribution License, which permits unrestricted use, distribution, and reproduction in any medium, provided the original work is properly cited.

\begin{abstract}
Surface grafting of biodegradable/biocompatible polylactide (PLA) films by a UV-assisted reaction has been developed by employing a hydrophilic acrylamide (Am) monomer, an $\mathrm{N}, \mathrm{N}^{\prime}$-methylenebisacrylamide (MBAm) cross-linker, and a camphorquinone (CQ)/N, $\mathrm{N}^{\prime}$-dimethylaminoethylmethacrylate (DMAEMA) photoinitiator/coinitiator system. The accomplishment of the process is confirmed by FTIR and XPS analyses. Physicochemical changes of the grafted PLA films are evaluated in terms of chemical structures, radiation-induced degradation followed by crystallization, morphology, thermal properties, and mechanical behavior. The results reveal that a low degree of PLA degradation through chain scission is observed in both blank and grafted PLA films. This generates more polar chain ends that can further induce crystallization. Results from contact angle measurements indicate that the grafted films have higher hydrophilicity and pH-responsive behavior. The incorporation of PAm on the film's surface and the induced crystallization lead to improvements in certain aspects of mechanical properties of the films. The materials have high potential for use in biomedical and environmental applications, such as cell culture substrates or scaffolds or pH-sensitive absorbents.
\end{abstract}

\section{Introduction}

Polylactide, PLA, is a versatile aliphatic thermoplastic polyester obtained from renewable sources [1]. The material is immensely attractive for industrial, packaging, agricultural, and biomedical applications, due to its outstanding properties, including biodegradability, biocompatibility, processability (techniques includes, extrusion, injection, blow molding, thermoforming, fiber spinning, or stretching), ecofriendliness (emit low carbon during its production), thermoplastic behavior (good shaping and molding capability), and comparable mechanical properties to petrochemical polymers (comparable to PET and better than PS) [1-4]. The material has been used in a wide range of applications, such as toxic metal adsorption, 3D printing, special coatings, dying, drug delivery system, cell attachment, and proliferation.

Despite its advantages, some of its shortcomings, such as poor adhesive properties due to hydrophobic surface, lack of functionality, low surface energy, and lack of side-chain groups for further modifications, make its use inadequate towards some specific applications. Therefore, surface modifications of this polymeric material are needed, which can open the door for those applications by increasing its surface hydrophilicity and functionality.

To improve surface adhesion properties of polymeric materials, irradiation and grafting techniques have been reported [5, 6], such as electrical discharge [7], ozonation and grafting [8], plasma treatments and surface grafting $[9,10]$, and also grafting through microwave [11] and UV irradiation [12]. These covalent grafting processes are very attractive as new desirable functional of different types can be introduced onto the polymer surfaces to change surface morphology, adhesiveness, and biocompatibility. For PLA, some research has been conducted on surface grafting with different materials $[13,14]$.

Polyacrylamide (PAm) is a nontoxic, low cost polymer produced from the radical polymerization of its vinyl 
monomer. During the synthesis, N,N'-methylenebisacrylamide can be applied to partially cross-link the polymer chains. This polymer shows its strong hydrophilic nature, due to the presence of polar amide groups. The material has been commonly used as a flocculant in water treatment and as a supporting matrix for gel electrophoresis. Recently, its use for grafting modification of hydrophobic surfaces has been widely reported, such as polyacrylamide-g-agar [15], polyacrylamide-g-Nylon 6,6 [16], polyacrylamide-g-chitosan [17], and polyacrylamide-g-graphene [18].

It is widely known that photografting of polymers through high-energy irradiation can create adverse effects on the bulk properties of the exposed substrates (e.g., gamma irradiation) [19] and in wet stage grafting (e.g., UV irradiation) $[20,21]$. The most common effects are the induction of cross-linking and degradation processes. In the modification of PLA, photodegradation by chain scission was observed $[19,21]$. To our knowledge, two studies investigated the grafting of PLA (particles and solution casting films) by acrylamide using benzophenone photoinitiator as a small part of respective full study [22, 23]. However, studies related to the quantitative analysis of the changes in bulk properties occurring during photografting of PLA (compressionmolded films) are rare.

The main purpose of this work is to develop poly(lactidegraft-acrylamide-co- $\mathrm{N}, \mathrm{N}^{\prime}$-methylenebisacrylamide), $\mathrm{P}(\mathrm{LA}-$ g-Am-co-MBAm) copolymer films that possess hydrophilic, reactive, and bioactive surfaces, by a UV-light assisted grafting reaction. PAm chains are grafted on and form a partial cross-linked structure by using cross-linker and coinitiator, along with photoinitiator, to speed up the reaction. The surface modification mechanisms and efficiency are characterized. Other physicochemical changes associated with the effect of UV irradiation, initiator, coinitiator, and solvent on the properties of the resulting PLA films are investigated. The materials have high potential for use in biomedical and environmental applications.

\section{Materials and Methods}

2.1. Materials. Commercial polylactide, PLA-4043D, was obtained from NatureWorks (USA). Acrylamide (Am) monomer and $\mathrm{N}, \mathrm{N}^{\prime}$-methylenebisacrylamide (MBAm) cross-linker were supplied by Acros (USA). Camphorquinone (CQ) photoinitiator (Esstech, USA) and $\mathrm{N}_{1} \mathrm{~N}^{\prime}$ dimethylaminoethylmethacrylate (DMAEMA) coinitiator (Fluka, USA) were used as received. Commercial grade methanol and ethanol solvents (Italmar, Thailand) and deionized water were used throughout the work. All chemicals were used without further purification.

2.2. Preparation of PLA Films. PLA films were prepared by using a compression molding machine (Chareontut, Thailand). The PLA pellets were heated up to $190^{\circ} \mathrm{C}$ and pressed at 2100 PSI for $14 \mathrm{~min}$, followed by air cooling to room temperature, to yield films with an average thickness of $0.22 \mathrm{~mm}$. The films were then cut into pieces $\left(5 \times 8 \mathrm{~cm}^{2}\right)$, termed as "neat" PLA film, and stored in a desiccator to avoid moisture absorption until further experiments.
2.3. Grafting Polymerization Procedure. A $10 \%$ (w/v) monomer solution was prepared by dissolving Am and MBAm at a weight ratio of 19:1 in methanol solvent. 0.1 g CQ and $0.1 \mathrm{~mL}$ DMAEMA (photoinitiator/coinitiator) were added at a ratio of $(\mathrm{Am}+\mathrm{MBAm}): \mathrm{CQ}: \mathrm{DMAEMA}=100: 1: 1$. It is noted that although DMAEMA can be used as a reactive monomer for forming of cross-link structures, the reagent was applied in a small amount in this study. Therefore, its possible cross-linking effect is negligible. The solution was sonicated for $1 \mathrm{~min}$ at room temperature. A blank solution was prepared by dissolving $0.1 \mathrm{~g}$ CQ and $0.1 \mathrm{~mL}$ DMAEMA in methanol. Photoactivation of PLA films was carried out by irradiating with UV-C $(254 \mathrm{~nm})$ using a UV lamp (ENF-260C/FE, Spectronics Corp., USA) for $20 \mathrm{~min}$ at room temperature. Essentially, neat PLA film was placed in a Petri dish and irradiated for $10 \mathrm{~min}$. The film was turned over to equally irradiate the opposite side. The distance from the UV lamp to the film surface was fixed at $2.3 \mathrm{~cm}$.

To synthesize P(LA-g-Am-co-MBAm) grafted copolymer film, $20 \mathrm{~mL}$ of monomer solution was poured into a Petri dish containing UV-activated PLA film. The whole system was further irradiated for $20 \mathrm{~min}$. The film was, then, washed with DI water and ethanol to remove residual monomer and ungrafted PAm chains. The films, passing through the photoinduced grafting polymerization, are defined as "grafted" PLA film. To perform "blank" experiments, $20 \mathrm{~mL}$ "blank" solution, consisting of only CQ and DMAEMA and methanol solvent, was poured into a Petri dish containing UV-activated PLA film, instead of monomer solution. The treated films are defined as "blank" PLA film. An overview of the synthesis process of the copolymer is shown in Figure 1.

2.4. Characterizations. The average molecular weights and molecular weight distributions of the neat, blank, and grafted PLA films were determined by gel permeation chromatography (GPC), using a Waters 150-CV gel permeation chromatograph. Monodispersed polystyrene was employed as a standard, and THF was used as a solvent, with a flow rate of $1 \mathrm{~mL} / \mathrm{min}$. The success of the photoinitiated grafting was verified by Fourier Transform Infrared (FTIR) spectroscopy on a Thermo Scientific Nicolet iS5 FTIR spectrometer equipped with iD5 Attenuated Total Reflectance (ATR) accessory. All spectra were recorded in both transmission and ATR modes, with 64 scans at a $2 \mathrm{~cm}^{-1}$ resolution.

X-Ray Photoelectron (XPS) spectroscopy was employed to characterize the chemical compositions of the surface. The measurements were performed on a PHI 5000 Versa Probe IIXPS system (ULVAC-PHI, Japan) with Al K radiation as the excitation source at the Synchrotron Light Research Institute (SLRI), Nakhon Ratchasima, Thailand. Contact angle measurements were performed to examine the degree of hydrophilicity of the film surfaces, through deionized water droplets at $3 \mathrm{pH}$ values: 4,7 , and 10 by adapting the method of Stalder et al. [24]. The digital images of water droplets were processed with the ImageJ software, using the DropSnake plug-in (Biomedical Imaging Group, EPFL). At least 10 replicates were measured for each film sample.

$\mathrm{X}$-ray diffraction spectroscopy (XRD) was conducted on the films for their crystalline content analysis. The 


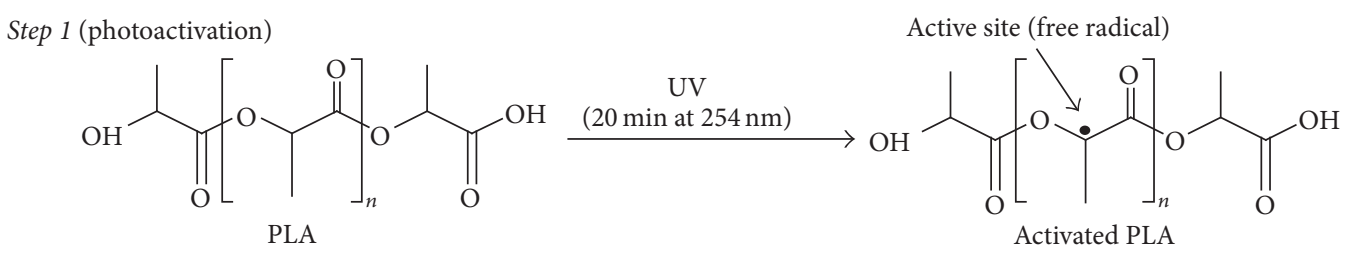

Step 2 (surface photografting)<smiles>C=CC(=O)NCNC(=O)C=C</smiles>

Activated PLA<smiles>CC12CCC(C(=O)C1=O)C2(C)C</smiles><smiles>C=C(C)C(=O)OCCN(C)C</smiles>

DMAEMA

$\mathrm{UV}(20 \mathrm{~min}$ at $254 \mathrm{~nm})$

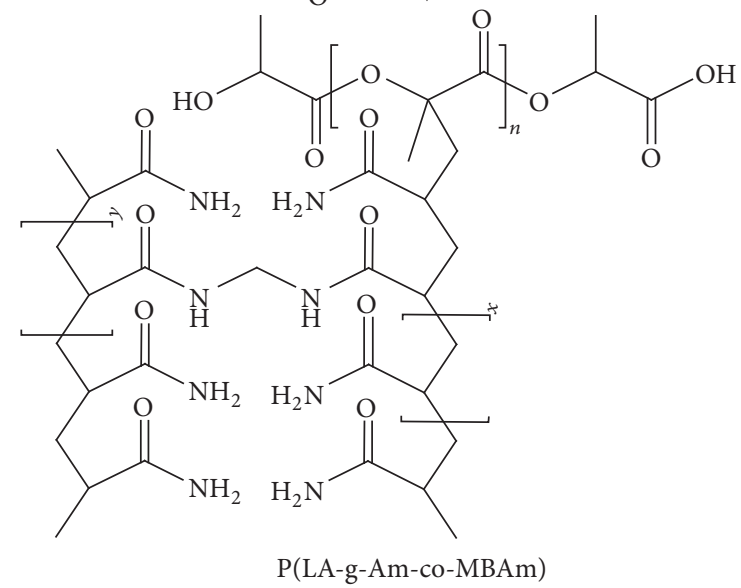

Here, $n=$ LA repeating unit $x=$ Am repeating unit $y=$ MBAm unit

Figure 1: Synthesis route of P(LA-g-Am-co-MBAm).

measurements were conducted on a JEOL JDX-3530 diffractometer, using a monochromatic $\mathrm{Cu} \mathrm{K} \alpha \mathrm{X}$-ray source at $40 \mathrm{kV}$ and $30 \mathrm{~mA}$. The samples were scanned from $2 \theta$ of $4-40^{\circ}$, with a 0.02 step size. Thermal behavior of the films was observed by Differential Scanning Calorimetry (DSC) on a DSC $822^{\mathrm{e}}$ Mettler Toledo instrument. The samples were scanned with a double cycle from -20 to $170^{\circ} \mathrm{C}$ at a heating/cooling rate of $10^{\circ} \mathrm{C} / \mathrm{min}$, under $\mathrm{N}_{2}$ atmosphere.

Cross-sectional topographies of the films were examined by Scanning Electron Microscopy (SEM) using a Hitachi SU8000 scanning microscope. The films were broken with the aid of liquid nitrogen. The samples were dried in a vacuum oven at $40^{\circ} \mathrm{C}$ overnight and sputter-coated with a $10 \mathrm{~nm}$ gold layer. Tensile properties of the film samples were examined using a universal tensile machine (Tinius Olsen: H5K-T UTM), according to ASTM D882-10, with a crosshead speed of $50 \mathrm{~mm} / \mathrm{min}$, using rectangle shaped specimens with $50 \mathrm{~mm}$ gauge length and $15 \mathrm{~mm}$ width. Prior to tensile testing, film specimens were conditioned in a vacuum oven at $25^{\circ} \mathrm{C}$
TABLE 1: GPC results of neat, blank, and grafted PLA films.

\begin{tabular}{lccc}
\hline \multirow{2}{*}{ Sample } & \multicolumn{3}{c}{ Average molecular weights } \\
& $\overline{\mathrm{M}} \mathrm{n}$ & $\overline{\mathrm{M}} \mathrm{w}$ & $\mathrm{PDI}$ \\
\hline Neat PLA & $9.6 \times 10^{4}$ & $2.0 \times 10^{5}$ & 2.1 \\
Blank PLA & $8.6 \times 10^{4}$ & $1.7 \times 10^{5}$ & 2.0 \\
Grafted PLA & $8.1 \times 10^{4}$ & $1.7 \times 10^{5}$ & 2.1 \\
\hline
\end{tabular}

for $24 \mathrm{~h}$. Data were taken from averaged values of at least 10 specimens for each sample.

\section{Results and Discussion}

3.1. GPC Measurements. GPC results reveal a significant effect of UV irradiation on PLA films in the presence of "blank" and monomer solutions. Table 1 summarizes the results of molecular weights (MW) of films after the treatment 


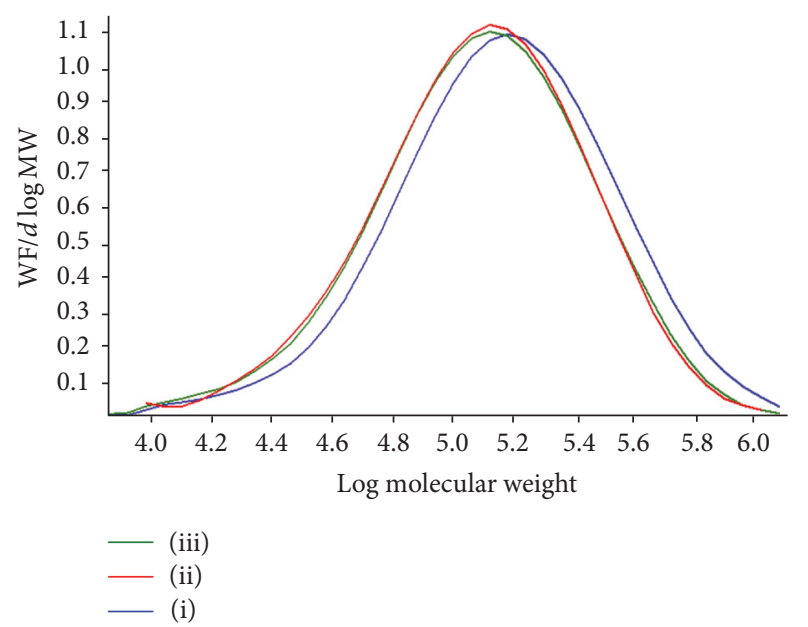

FIGURE 2: GPC chromatograms of neat (i), blank (ii), and grafted PLA (iii) films.

for $40 \mathrm{~min}$. A decrease in MW from a neat PLA film to blank PLA film (around 10\%) and to grafted PLA film (roughly 16\%) is observed. This is attributed to an increase in the content of low MW fragments, as a result from chain scissions during the treatment.

However, no secondary peaks can be observed in GPC chromatograms, as shown in Figure 2, and the polydispersity index (PDI) value remains relatively stable, between 2.0 and 2.1. This strongly suggests that chain scissions occur randomly along the chains and confirms that degradation occurs homogeneously through the film thickness.

3.2. FTIR Spectroscopy. Chemical structures and chain conformations are characterized by ATR-FTIR spectroscopy. Figure 3(a) shows spectra in the characteristic region of $\mathrm{O}-\mathrm{H}$ and $\mathrm{N}-\mathrm{H}$ stretching and $\mathrm{C}=\mathrm{O}$ overtone modes. Sharp bands, located at $3700-3450 \mathrm{~cm}^{-1}$, are associated with overtone combination modes. Difference spectra are also shown to provide clearer spectral changes. A new positive difference band, appearing after the blank and grafting treatments at $3294 \mathrm{~cm}^{-1}$, is due to O-H stretching mode of newly generated $-\mathrm{OH}$ and $-\mathrm{COOH}$ end groups as a result from partial degradation by UV irradiation. A band at $3383 \mathrm{~cm}^{-1}$, observed only after the grafting treatment, is associated with the N-H asymmetric stretching mode of PAm, which can be used for quantitative measurement of the grafting content. The $\mathrm{N}-\mathrm{H}$ symmetric stretching mode is overlapped with the stretching band of free $\mathrm{O}-\mathrm{H}$ groups at around $3213 \mathrm{~cm}^{-1}$. On the difference spectra, N-H symmetric stretching band is located at $3198 \mathrm{~cm}^{-1}$.

There is also a positive difference band at $1692 \mathrm{~cm}^{-1}$ (amide I), as shown in Figure 3(b), confirming the presence of the grafted acrylamide chains. An amide II mode is observed as a weak broad band at around $1599 \mathrm{~cm}^{-1}$, while a C$\mathrm{N}$ stretching mode (amide III) appears at $1417 \mathrm{~cm}^{-1}$ in the subtracted spectra of the grafted sample.

FTIR spectra recorded in ATR mode in the C-H stretching region are shown in Figure 4(a). Neat PLA shows bands at 2995 and $2945 \mathrm{~cm}^{-1}$ of the asymmetric and symmetric stretching of $-\mathrm{CH}_{3}$ groups and at $2880 \mathrm{~cm}^{-1}$ of the stretching mode of - $\mathrm{CH}$ groups, whose relative intensities slightly decrease in the blank and grafted samples. After treatments, 2 new bands are developed at 2917 and $2850 \mathrm{~cm}^{-1}$, indicating the presence of new C-H vibrations of LA end groups [25]. This is likely a result from partial degradation and structural changes of PLA chains.

It is well known that the $\mathrm{C}=\mathrm{O}$ stretching mode of PLA is sensitive to its structure and chain conformation [26, 27]. The samples subjected to blank and grafting experiments show splitting $\mathrm{C}=\mathrm{O}$ bands at 1756 and $1746 \mathrm{~cm}^{-1}$, as shown in Figure 4(b), corresponding to a gauche-trans (gt) crystalline conformation and an amorphous structure, respectively [28]. In contrast, a broader single amorphous band is observed in the neat sample. This confirms the formation of crystalline domains after the treatments.

In addition, bands at 988 and $809 \mathrm{~cm}^{-1}$ (the out-of-plane bending of $\mathrm{N}-\mathrm{H}$ ), as depicted in Figure 4(c), can also be used to quantitatively confirm the presence of PAm and its content. An amorphous characteristic band at $956 \mathrm{~cm}^{-1}$ shows a decrease in intensity in the blank and grafted films, compared to neat PLA. Simultaneously, a sharp PLA $\alpha$-crystal's band appears at $921 \mathrm{~cm}^{-1}$ in the 2 treated films $[29,30]$. The results firmly ensure that there is a significant transformation of amorphous phase to crystalline domains, due to conformational changes induced by newly formed $-\mathrm{OH}$ and $-\mathrm{COOH}$ terminals, as observed in GPC results.

3.3. XPS Analysis. XPS spectra of neat PLA and PAm-grafted PLA surfaces are compared. Figures 5(a) and 5(b) show 2 strong signals of $\mathrm{Cls}$ and O1s for the surfaces of both samples, while a distinct N1s signal of PAm is only observed in the grafted sample [31,32]. The presence of this signal ultimately indicates the success of the photografting reaction. Figure 5(c) shows 3 bands associated with $\mathrm{C}-\mathrm{C} / \mathrm{C}-\mathrm{H}, \mathrm{C}-\mathrm{O}$, and $\mathrm{O}-\mathrm{C}=\mathrm{O}$ components, in the $\mathrm{Cl}$ s region [10]. The relative intensity of the $\mathrm{C}-\mathrm{C} / \mathrm{C}-\mathrm{H}$ component increases as a result from the grafting reaction, while those of the other 2 bands of $\mathrm{C}-\mathrm{O}, \mathrm{O}-\mathrm{C}=\mathrm{O}$ components decrease. This is because the incorporation of PAm on the PLA surface leads to a decrease in relative contents of ester $\mathrm{C}-\mathrm{O}$ and $\mathrm{O}-\mathrm{C}=\mathrm{O}$, but an increase in the $C-\mathrm{C} / \mathrm{C}-\mathrm{H}$ composition $[33,34]$. The corresponding $\mathrm{O} 1 \mathrm{~s}$ signals, as shown in Figure 5(d), reflect the surface contents of $\mathrm{O}-\mathrm{C}=\mathrm{O}$ and $\mathrm{C}-\mathrm{O}$ groups [35]. Both signals show a decrease in intensities from neat PLA to the grafted film, because of a dilution effect from the presence of PAm. The existence of amide oxygen, $\mathrm{N}-\mathrm{C}=\mathrm{O}$, is visible as a weak shoulder, located at the lower energy region of the $\mathrm{O}-\mathrm{C}=\mathrm{O}$ band of the grafted film. This is also confirmed by an appearance of the distinct signal of N1s, as shown in Figure 5(e).

3.4. Surface Properties. Contact angle measurements are used to characterize surface wettability and $\mathrm{pH}$-responsive behavior of the samples. The contact angle (CA) values were measured at $25^{\circ} \mathrm{C}$ by using water droplets at $\mathrm{pH}$ of 4,7 , and 10 . The results, as summarized in Figure 6, show that neat PLA film has a CA value of $68^{\circ}$, reflecting its slightly hydrophilic 


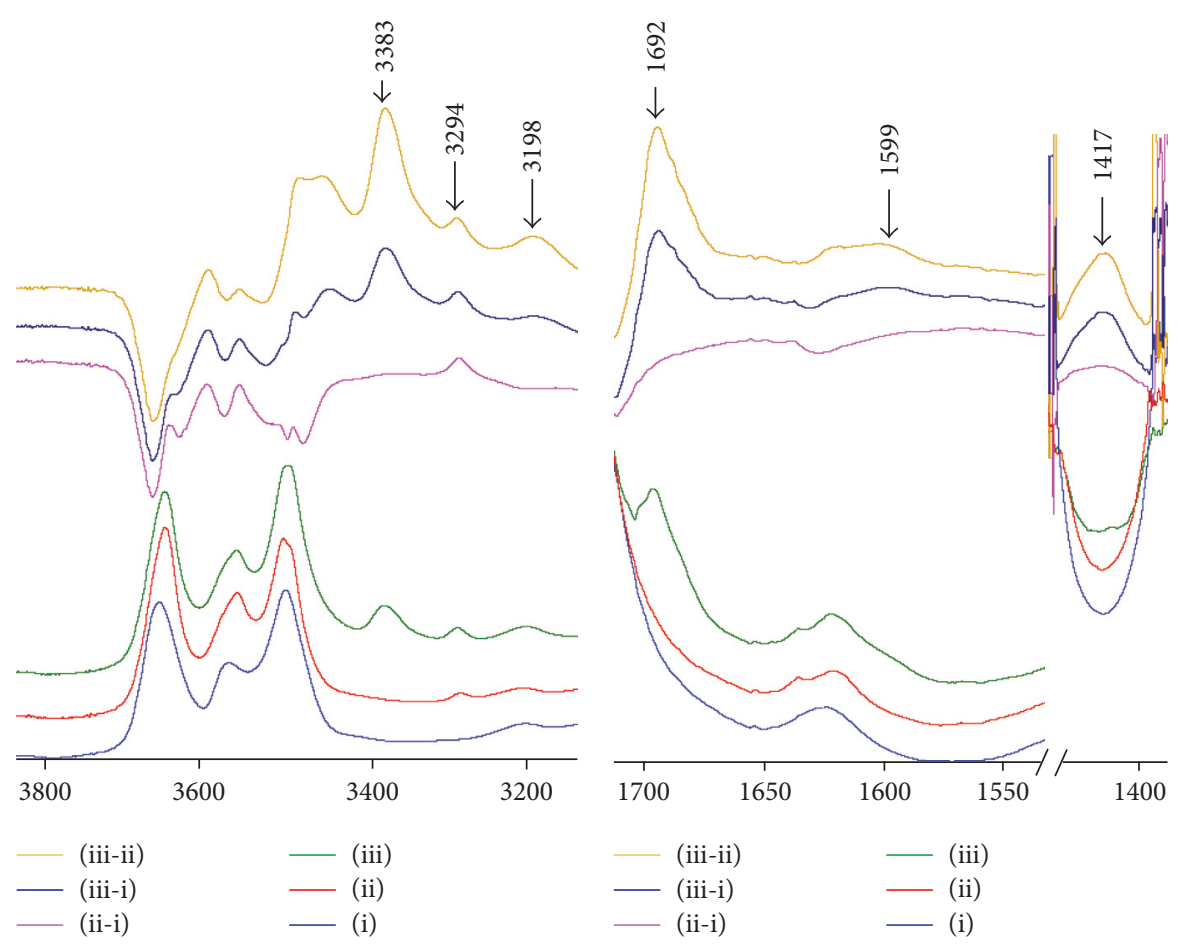

(a)

(b)

FIGURE 3: FTIR (transmission) spectra of neat (i), blank (ii) and grafted PLA (iii) films. Subtracted (difference) FTIR spectra of the corresponding samples are shown on the upper part.

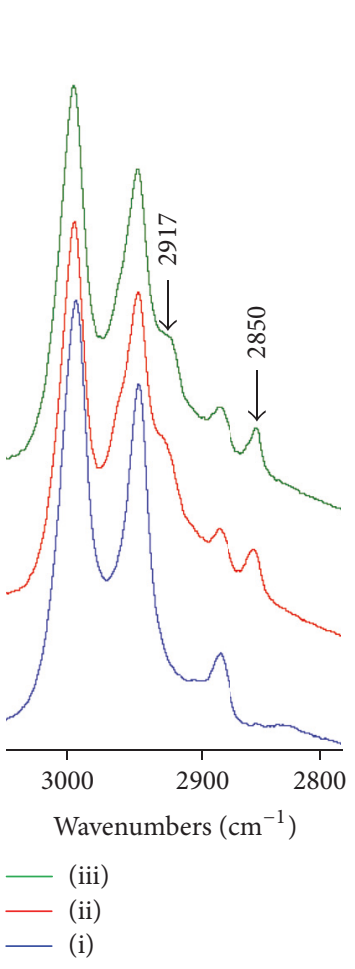

(a) ATR

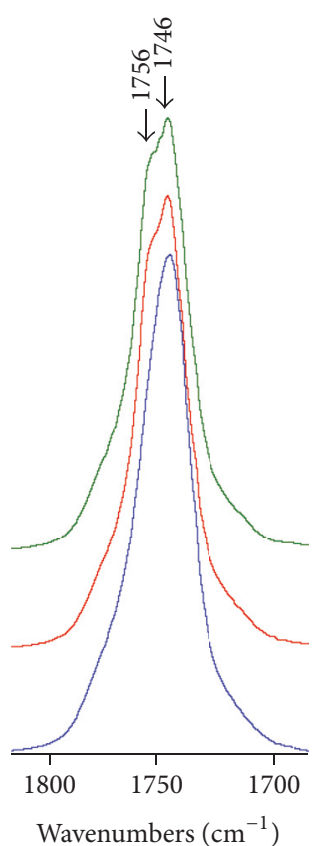

- (iii)

- (ii)

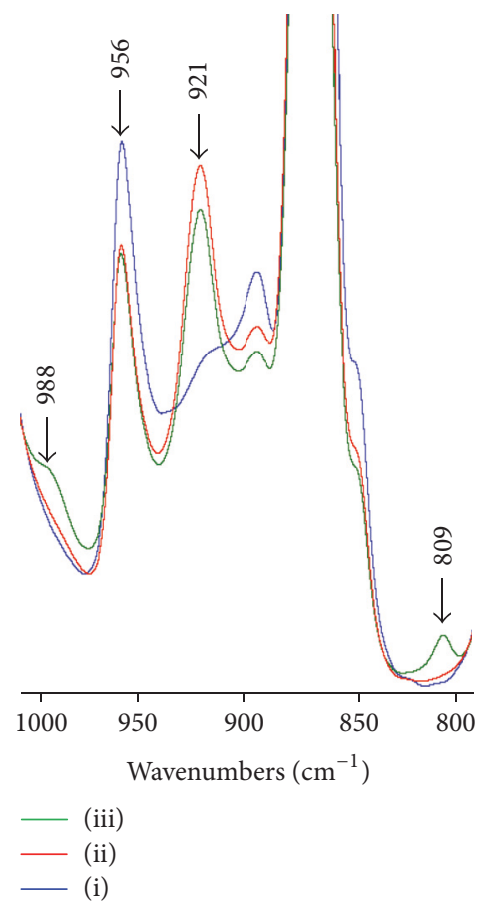

(c) Transmission

FIGURE 4: FTIR spectra of neat (i), blank (ii), and grafted PLA (iii) films in the C-H stretching vibrational region (a), the C=O stretching vibration region (b), and the skeletal vibration region (c), indicating changes in conformations and crystalline characteristics of the film samples. 


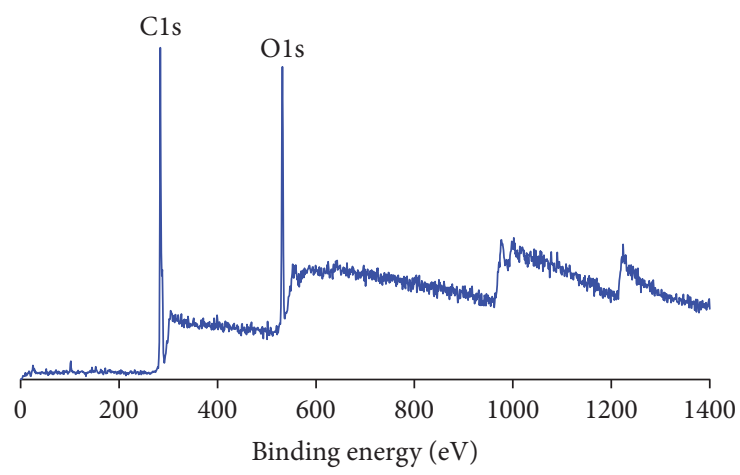

— Neat PLA film

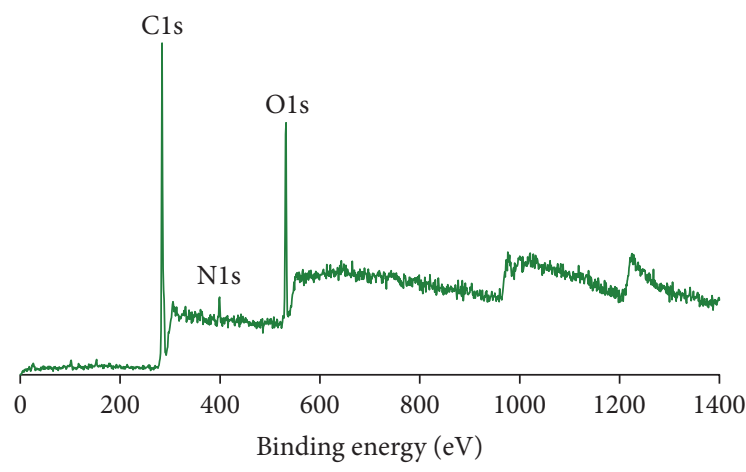

— Grafted PLA film

(a)

(b)

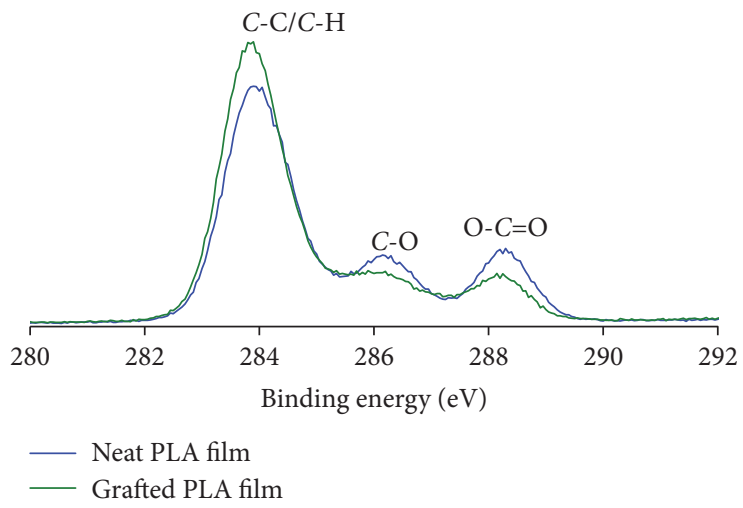

(c)

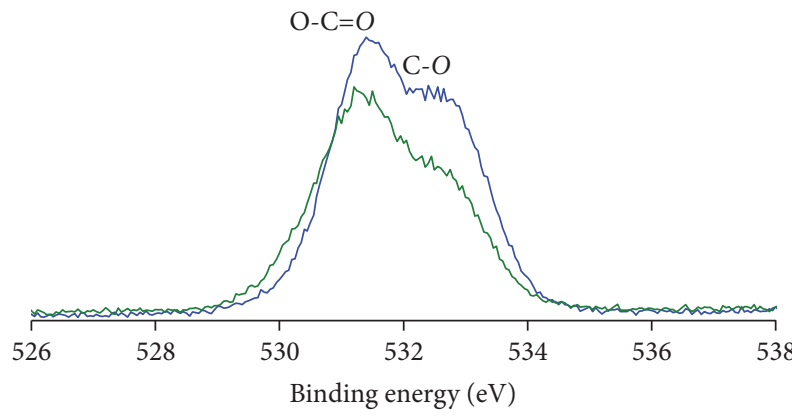

— Neat PLA film Grafted PLA film

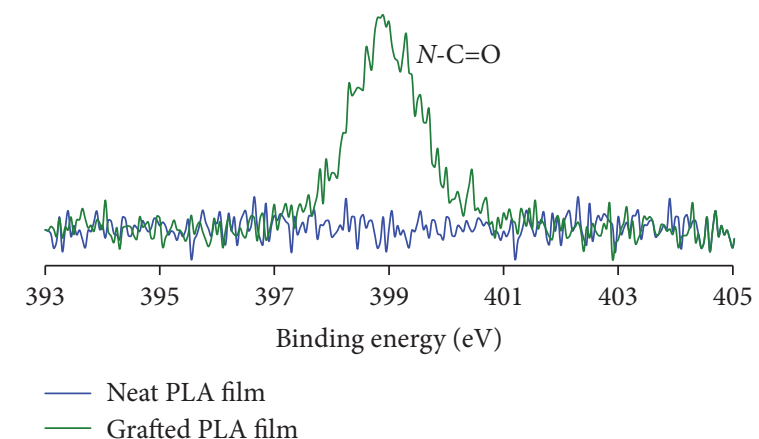

(e)

FIGURE 5: XPS spectra of neat (a) and grafted PLA (b) films (full spectra) and expanded scaled spectra in the C1s (c), O1s (d), and N1s (e) regions of neat and grafted PLA films.

nature compared to other polyolefin. Upon treating with "blank" or monomer solutions, the resulting films exhibit lower CA values, indicating higher degree of hydrophilicity. The results confirm that treating PLA films with blank solutions under UV irradiation leads to slight chain scissions and formation of newly generated polar $-\mathrm{OH}$ and $-\mathrm{COOH}$ end groups and hence an increase in the surface hydrophilicity. Further decrease in the CA value is observed in grafted PLA film, as a result from the presence of both grafted PAm chains and the newly generated PLA polar end groups.

Interestingly, $\mathrm{pH}$-dependent behavior is observed in "blank" and grafted PLA films, whereas the CA values measured at different $\mathrm{pH}$ for neat film remain significantly unchanged. The lowest CA values of the 2 treated samples are observed at $\mathrm{pH} 4$, which slightly increase when a neutral solution is employed. However, a sharp increase in the value is obtained when the $\mathrm{pH}$ of the water droplet is increased to 10. The results confirm that both treated films have negative polarity surfaces, due to the presence of grafted functional groups and newly generated end groups, as already described. At acidic and neutral $\mathrm{pH}$, interaction between the positively charged species in the water droplet and the negative polarity surface leads to higher wettability. In contrast, at high $\mathrm{pH}$ values, the presence of $\mathrm{OH}^{-}$results in strong repulsion of 


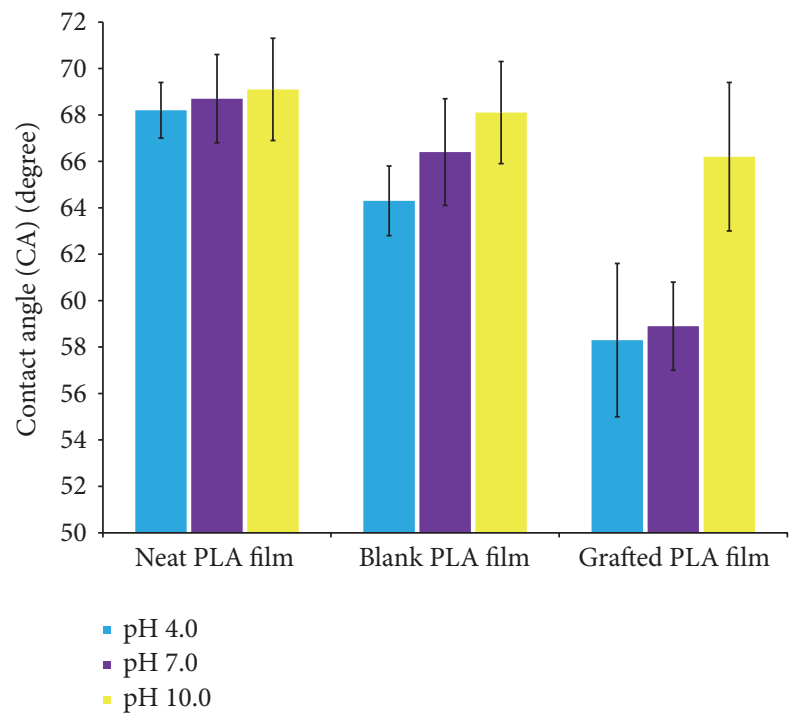

FIGURE 6: Contact angle (CA) values of neat, blank, and grafted PLA films, measured by using water droplets at various $\mathrm{pH}$ values.

the water droplet and the film surface, reflecting by a higher CA value or lower wettability. In addition, the degree of $\mathrm{pH}$-dependent property also increases from blank to grafted films, due to an increase in the content of surface negative functionalities.

3.5. XRD Spectroscopy. Crystalline characteristics of films before and after treatments are examined. It is clearly observed that after blank and grafting processes, the films became opaque (almost completely white), whereas neat PLA film is transparent. This is due to formation of crystalline domains in the films. To verify this and calculate the crystalline contents of the samples, XRD is employed and the diffractograms are shown in Figure 7. Neat PLA has almost completely amorphous structure, as a very weak diffraction peak at $2 \theta=16.8^{\circ}$ is observed. In contrast, 4 characteristic sharp peaks appear in the blank and grafted films at $2 \theta=14.9^{\circ}$, $16.7^{\circ}, 19.1^{\circ}$, and $22.4^{\circ}$, corresponding to (010), (110/200), (203), and (205) planes, reflecting their semicrystalline nature [36, 37]. Results on crystallinity (\%) show that the neat sample has only $2 \%$ crystalline content, whereas a considerable increase in the values to $35 \%$ and $29 \%$ is observed in the blank and grafted counterparts. The value for the blank sample is slightly higher than the grafted films, indicating that the grafting of PAm on the film surface may interrupt PLA's chain arrangement and, hence, lower its degree of crystallinity.

3.6. Thermal Properties. Effects of grafting polymerization on thermal properties of the films are investigated by DSC, as presented in Figure 8. The glass transition temperature $\left(T_{\mathrm{g}}\right)$ and melting temperatures $\left(T_{\mathrm{m}}\right)$ of the samples are identified. Double melting endothermic peaks are clearly witnessed in the grafted PLA film $\left(142.7\right.$ and $\left.152.7^{\circ} \mathrm{C}\right)$, whereas, in the neat $\left(138.7^{\circ} \mathrm{C}\right)$ and blank $\left(146.7^{\circ} \mathrm{C}\right)$ samples, a single $T_{\mathrm{m}}$ is observed. These split endotherms are associated with two distinct crystalline structures of PLA: disordered imperfect $\alpha^{\prime}$

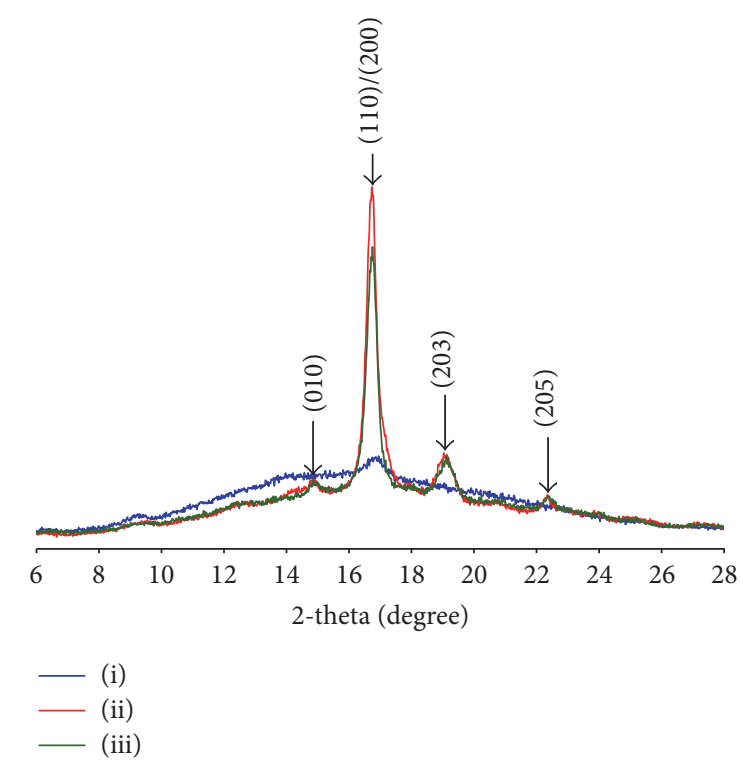

FIGURE 7: XRD diffractograms of neat (i), blank (ii), and grafted PLA (iii) films.

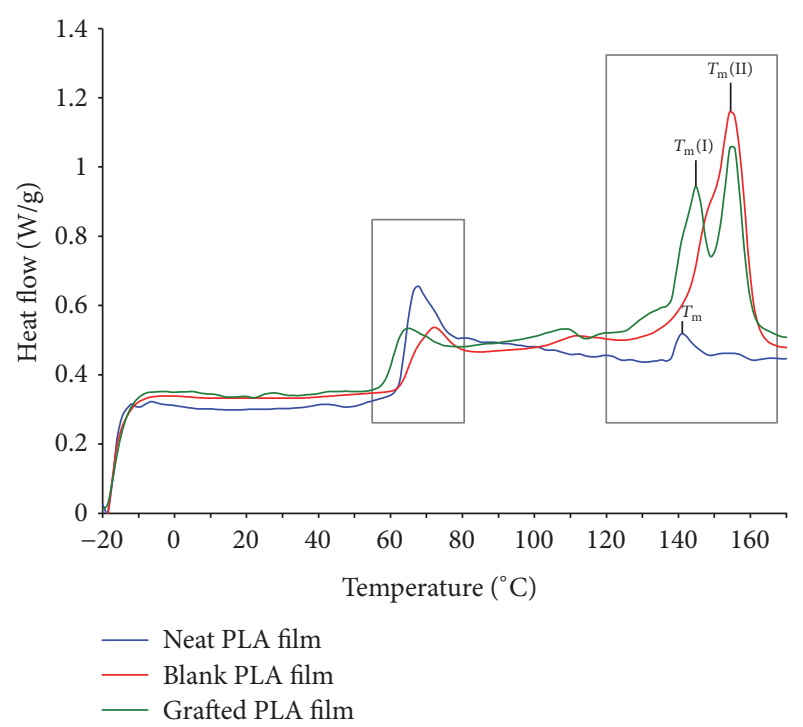

FIGURE 8: DSC thermograms (1st heating curve) of neat, blank, and grafted PLA films.

crystalline and ordered perfect $\alpha$ crystalline forms. The lower endotherm $T_{\mathrm{m}}(\mathrm{I})$ is related to the $\alpha^{\prime}$ form which is generated under restricted conditions. This form almost simultaneously recrystallizes into $\alpha$ form when the restricted conditions are released. The higher $T_{\mathrm{m}}$ (II) corresponds to the perfect crystals from reorganization and the primary $\alpha$ form. The two processes, the melting of the $\alpha^{\prime}$ form and the recrystallization into $\alpha$ form, can be considered as the $\alpha^{\prime}-\alpha$ phase transition. This phase transition was hindered in the grafted sample, however, due to chain entanglements by PAm on the PLA surface. Subsequently, thickening of the imperfect $\alpha^{\prime}$ crystal form occurs. 

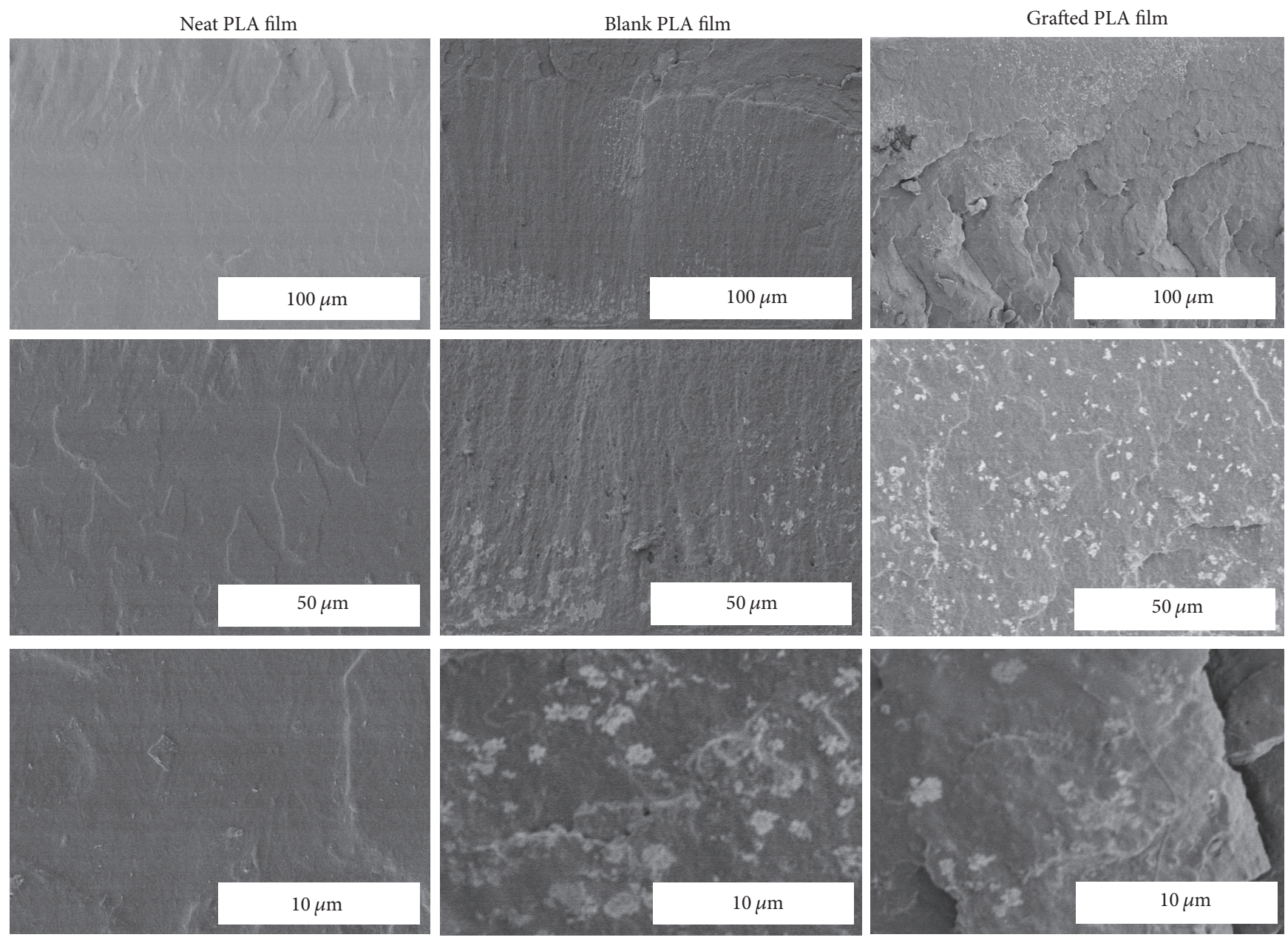

FIGURE 9: Cross-sectional SEM micrographs of neat, blank, and grafted PLA films at different magnifications.

TABLE 2: Thermal properties derived from DSC (1st heating) experiments of neat, blank, and grafted PLA films.

\begin{tabular}{lccccc}
\hline Sample & $\begin{array}{c}T_{\mathrm{g}} \\
\left({ }^{\circ} \mathrm{C}\right)\end{array}$ & $\begin{array}{c}T_{\mathrm{m}}(\mathrm{I}) \\
\left({ }^{\circ} \mathrm{C}\right)\end{array}$ & $\begin{array}{c}T_{\mathrm{m}}(\mathrm{II}) \\
\left({ }^{\circ} \mathrm{C}\right)\end{array}$ & $\begin{array}{c}\Delta H_{\mathrm{m}} \\
(\mathrm{J} / \mathrm{g})\end{array}$ & $\begin{array}{c}X_{\mathrm{c}} \\
(\%)\end{array}$ \\
\hline Neat PLA & 62.3 & 138.7 & 153.7 & 1.36 & 2 \\
Blank PLA & 64.4 & 146.7 & 152.7 & 24.20 & 26 \\
Grafted PLA & 59.0 & 142.7 & 152.7 & 20.98 & 23 \\
\hline
\end{tabular}

The degree of crystallinity $\left(X_{c}\right)$ was also calculated from the enthalpy of melting of 1st heating thermograms by comparing with semicrystalline PLA measured at the equilibrium point $(93.0 \mathrm{~J} / \mathrm{g}$ ) [38]. The results, as summarized in Table 2, show an increase in the crystalline contents from $2 \%$ for neat PLA to $26 \%$ for blank and 23\% for grafted films. This agrees with those observed in XRD experiments, reflecting a transformation of amorphous PLA structures to crystalline domains during the blank and grafting treatments. The blank and grafted films exhibit slightly higher $\left(64.4^{\circ} \mathrm{C}\right)$ and lower $\left(59.0^{\circ} \mathrm{C}\right) T_{\mathrm{g}}$, compared to the intermediate value of neat PLA $\left(62.3^{\circ} \mathrm{C}\right)$. Generally, $T_{\mathrm{g}}$ value increases with an increase in crystallinity and decreases with the introduction of plasticizers to the polymer matrix. Although crystalline domains are developed in both the blank and grafted films, the grafted film shows lower $T_{\mathrm{g}}$. This is likely because the medium-sized grafted PAm chains, which contain a high content of chain ends, can act as a plasticizer for the PLA matrix.

3.7. Morphology. The cross-sectional areas of all films are analyzed by SEM to observe morphological changes before and after blank and grafting experiments. SEM micrographs at different magnifications of the blank and grafted films show profound morphological changes, that is, transition from complete amorphous to semicrystalline structures, as observed as white crystalline domains dispersed over the whole cross-sectional area, as shown in Figure 9. It is, therefore, concluded that the crystallization mechanisms involve nucleation steps from the initiator, coinitiator, and methanol solvent molecules, which penetrate into the film matrix, and also local induced crystallization by $-\mathrm{OH}$ and $-\mathrm{COOH}$ chain ends, generated from a low degree of chain scissions.

3.8. Mechanical Properties. Mechanical properties of all films are examined by tensile experiments. The properties typically 


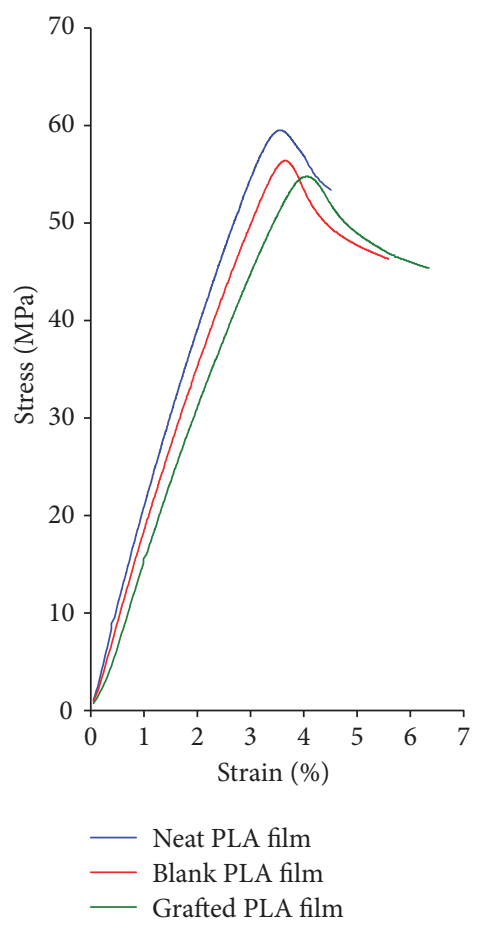

(a)

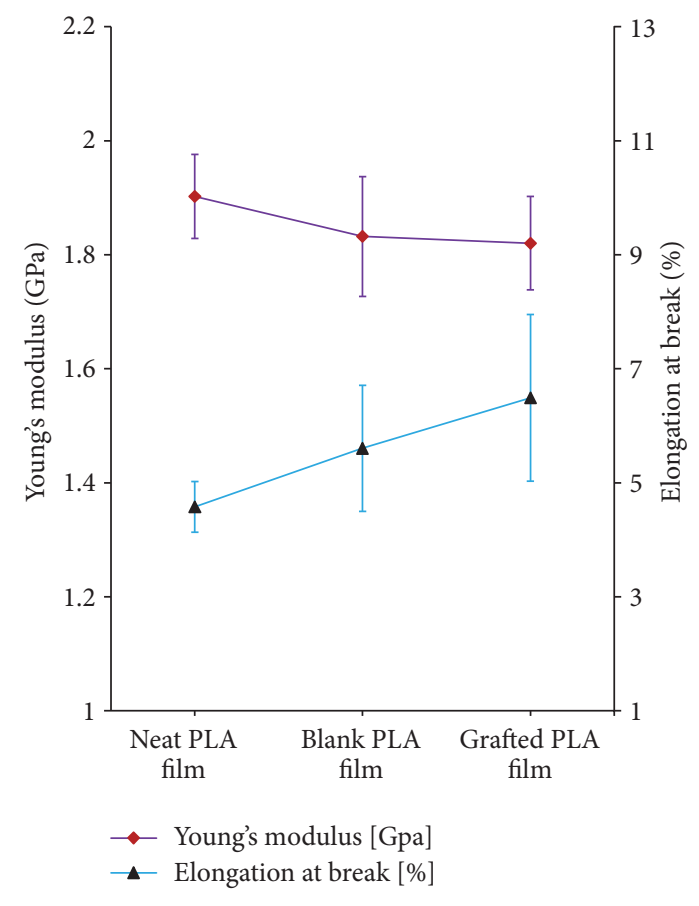

(b)

FIGURE 10: Stress-strain curves (a) and Young's modulus and elongation at break values (b) of neat, blank, and grafted PLA films.

correlate with chemical structures, molecular weights, and crystallinity of polymers. All PLA films exhibit the stressstrain behavior of normal plastic materials, in which yielding is observed before breaking, as shown in Figure 10. The tensile strength of the samples shows a slight drop, whereas stress at break exhibits a moderate rise from neat to blank and grafted films. The drops in tensile strength and Young's modulus are directly related to the partial chain scissions of PLA, which have taken place in both blank and grafted films. Although enhancement of crystallinity in those 2 films is observed, the effect of molecular weights reduction overwhelmed the crystalline effect in this case.

In contrast, the elongation at break of the 2 treated samples increases sharply, compared to neat film. This can be explained in terms of a toughening effect from the presence of crystalline domains, which act as physical cross-links holding the chains before rapture. Moreover, the grafted PLA film exhibits a higher elongation at break value than the blank film. This is likely because of the presence of slightly crosslinked $\mathrm{P}(\mathrm{Am}-\mathrm{co}-\mathrm{MBAm})$ grafted chains on the film surface.

\section{Conclusions}

P(LA-g-Am-co-MBAm) films were successfully prepared by UV-assisted graft polymerization. The grafted PLA surface becomes more hydrophilic, compared to its blank and neat PLA film counterparts. The surface also exhibits $\mathrm{pH}$ dependent properties, due to the presence of the grafted PAm chains. The treatments of both blank and Am monomer solutions under UV irradiation trigger slight photodegradation and subsequent induced crystallization of the blank and grafted films, which have significant effects on the molecular structure, morphological, thermal, mechanical properties, and crystallinity of the films. The materials have high potential for use in biomedical applications, such as cell culture substrates or scaffolds which are responsive to $\mathrm{pH}$ changes, or in environmental applications as absorbents for various contaminant species.

\section{Conflicts of Interest}

The authors declare that there are no conflicts of interest regarding the publication of this paper.

\section{Authors' Contributions}

All authors have seen and approved the submission of this manuscript.

\section{Acknowledgments}

The authors acknowledge financial support from the National Research University (NRU) grant, provided from the Office of Higher Education Commission (OHEC) and the Center of Excellence in Materials and Plasma Technology (M@P Tech), Thammasat University. The authors are grateful to Dr. Narong Chanlek, Beamline Scientist, Synchrotron Light Research Institute (SLRI), Nakhon Ratchasima, Thailand, for XPS 
experiments. Mijanur Rahman acknowledges the support from the Graduate Scholarship Program for Excellent Foreign Students (EFS) scholarship by SIIT.

\section{References}

[1] R. E. Drumright, P. R. Gruber, and D. E. Henton, "Polylactic acid technology," Advanced Materials, vol. 12, no. 23, pp. 1841-1846, 2000.

[2] Y. Tokiwa and B. P. Calabia, "Biodegradability and biodegradation of poly(lactide)," Applied Microbiology and Biotechnology, vol. 72, no. 2, pp. 244-251, 2006.

[3] Y.-P. Hao, H.-H. Ge, L.-J. Han, H.-L. Zhang, L.-S. Dong, and S.-L. Sun, "Thermal and mechanical properties of polylactide toughened with a butyl acrylate-ethyl acrylate-glycidyl methacrylate copolymer," Chinese Journal of Polymer Science, vol. 31, no. 11, pp. 1519-1527, 2013.

[4] R. Auras, B. Harte, and S. Selke, "An overview of polylactides as packaging materials," Macromolecular Bioscience, vol. 4, no. 9, pp. 835-864, 2004.

[5] K. Kato, E. Uchida, E.-T. Kang, Y. Uyama, and Y. Ikada, "Polymer surface with graft chains," Progress in Polymer Science, vol. 28, no. 2, pp. 209-259, 2003.

[6] S. Minko, "Grafting on solid surfaces: 'grafting to' and 'grafting from' methods," in Polymer Surfaces and Interfaces: Characterization, Modification and Applications, M. Stamm, Ed., pp. 215234, Springer, Berlin, Germany, 2008.

[7] A. R. Blythe, D. Briggs, C. R. Kendall, D. G. Rance, and V. J. I. Zichy, "Surface modification of polyethylene by electrical discharge treatment and the mechanism of autoadhesion," Polymer Journal, vol. 19, no. 11, pp. 1273-1278, 1978.

[8] K. Fujimoto, Y. Takebayashi, H. Inoue, and Y. Ikada, "Ozone-induced graft polymerization onto polymer surface," Journal of Polymer Science Part A: Polymer Chemistry, vol. 31, no. 4, pp. 1035-1043, 1993.

[9] B. Hergelová, A. Zahoranová, D. Kováčik, M. Stupavská, and M. Černák, "Polylactic acid surface activation by atmospheric pressure dielectric barrier discharge plasma," Open Chemistry, vol. 13, no. 1, pp. 564-569, 2015.

[10] T. Jacobs, H. Declercq, N. De Geyter et al., "Plasma surface modification of polylactic acid to promote interaction with fibroblasts," Journal of Materials Science: Materials in Medicine, vol. 24, no. 2, pp. 469-478, 2013.

[11] C.-X. Lin, H.-Y. Zhan, M.-H. Liu, S.-Y. Fu, and L.-H. Huang, "Rapid homogeneous preparation of cellulose graft copolymer in bmimcl under microwave irradiation," Journal of Applied Polymer Science, vol. 118, no. 1, pp. 399-404, 2010.

[12] A. K. Mukherjee, H. S. Sachdev, and A. Gupta, "Photoinduced graft copolymerization of nylon 6 fibers with acrylamide. I. Effect of synthesis conditions," Journal of Applied Polymer Science, vol. 28, no. 6, pp. 2125-2129, 1983.

[13] M. H. Gutiérrez-Villarreal and J. G. Guzmán-Moreno, "Surface graft polymerization of $\mathrm{N}$-vinylcaprolactam onto polylactic acid film by UV irradiation," Journal of Polymer Research, vol. 20, no. 6, pp. 1-6, 2013.

[14] M. H. Gutierrez-Villarreal, M. G. Ulloa-Hinojosa, and J. G. Gaona-Lozano, "Surface functionalization of poly(lactic acid) film by UV-photografting of N-vinylpyrrolidone," Journal of Applied Polymer Science, vol. 110, no. 1, pp. 163-169, 2008.

[15] G. U. Rani, S. Mishra, G. Sen, and U. Jha, "Polyacrylamide grafted Agar: Synthesis and applications of conventional and microwave assisted technique," Carbohydrate Polymers, vol. 90, no. 2, pp. 784-791, 2012.

[16] X. Li, X. Gu, S. Zhang et al., "Improving the fire performance of nylon 6,6 fabric by chemical grafting with acrylamide," Industrial \& Engineering Chemistry Research, vol. 52, no. 6, pp. 22902296, 2013.

[17] S. G. Kumbar, K. S. Soppimath, and T. M. Aminabhavi, "Synthesis and characterization of polyacrylamide-grafted chitosan hydrogel microspheres for the controlled release of indomethacin," Journal of Applied Polymer Science, vol. 87, no. 9, pp. 15251536, 2003.

[18] Z. Xu, Y. Zhang, X. Qian et al., "One step synthesis of polyacrylamide functionalized graphene and its application in $\mathrm{Pb}$ (II) removal," Applied Surface Science, vol. 316, no. 1, pp. 308314, 2014.

[19] P. Nugroho, H. Mitomo, F. Yoshii, and T. Kume, "Degradation of poly(L-lactic acid) by $\gamma$-irradiation," Polymer Degradation and Stability, vol. 72, no. 2, pp. 337-343, 2001.

[20] N. Yasuda, Y. Wang, T. Tsukegi, Y. Shirai, and H. Nishida, "Quantitative evaluation of photodegradation and racemization of poly(l-lactic acid) under UV-C irradiation," Polymer Degradation and Stability, vol. 95, no. 7, pp. 1238-1243, 2010.

[21] A. Copinet, C. Bertrand, S. Govindin, V. Coma, and Y. Couturier, "Effects of ultraviolet light $(315 \mathrm{~nm})$, temperature and relative humidity on the degradation of polylactic acid plastic films," Chemosphere, vol. 55, no. 5, pp. 763-773, 2004.

[22] U. Edlund, M. Källrot, and A.-C. Albertsson, "Single-step covalent functionalization of polylactide surfaces," Journal of the American Chemical Society, vol. 127, no. 24, pp. 8865-8871, 2005.

[23] R. W. N. Nugroho, K. Odelius, A. Höglund, and A.-C. Albertsson, "Nondestructive covalent 'grafting-from' of poly(lactide) particles of different geometries," ACS Applied Materials \& Interfaces, vol. 4, no. 6, pp. 2978-2984, 2012.

[24] A. F. Stalder, G. Kulik, D. Sage, L. Barbieri, and P. Hoffmann, "A snake-based approach to accurate determination of both contact points and contact angles," Colloids and Surfaces A: Physicochemical and Engineering Aspects, vol. 286, no. 1-3, pp. 92-103, 2006.

[25] S. Bocchini and A. Frache, "Comparative study of filler influence on polylactide photooxidation," Express Polymer Letters, vol. 7, no. 5, pp. 431-442, 2013.

[26] P. Opaprakasit, M. Opaprakasit, and P. Tangboriboonrat, "Crystallization of polylactide and its stereocomplex investigated by two-dimensional fourier transform infrared correlation spectroscopy employing carbonyl overtones," Applied Spectroscopy, vol. 61, no. 12, pp. 1352-1358, 2007.

[27] G. Socrates, Infrared Characteristic Group Frequencies: Tables and Charts, Wiley, Chichester, UK, 1994.

[28] S.-T. Hsu and Y. L. Yao, "Effect of film formation method and annealing on crystallinity of poly(L-lactic acid) films," Journal of Manufacturing Science and Engineering, Transactions of the ASME, vol. 136, no. 2, Article ID 021006, 2011.

[29] D. Rasselet, A. Ruellan, A. Guinault, G. Miquelard-Garnier, C. Sollogoub, and B. Fayolle, "Oxidative degradation of polylactide (PLA) and its effects on physical and mechanical properties," European Polymer Journal, vol. 50, no. 1, pp. 109-116, 2014.

[30] E. Meaurio, N. López-Rodríguez, and J. R. Sarasua, "Infrared spectrum of poly(L-lactide): Application to crystallinity studies," Macromolecules , vol. 39, no. 26, pp. 9291-9301, 2006. 
[31] J. Fan, Z. Shi, M. Lian, H. Li, and J. Yin, "Mechanically strong graphene oxide/sodium alginate/polyacrylamide nanocomposite hydrogel with improved dye adsorption capacity," Journal of Materials Chemistry A, vol. 1, no. 25, pp. 7433-7443, 2013.

[32] H.-X. Wu, L. Tan, M.-Y. Yang, C.-J. Liu, and R.-X. Zhuo, "Protein-resistance performance of amphiphilic copolymer brushes consisting of fluorinated polymers and polyacrylamide grafted from silicon surfaces," RSC Advances, vol. 5, no. 16, pp. 1232912337, 2015.

[33] A. J. Antończak, B. D. Stępak, K. Szustakiewicz, M. R. Wójcik, and K. M. Abramski, "Degradation of poly(l-lactide) under CO2 laser treatment above the ablation threshold," Polymer Degradation and Stability, vol. 109, pp. 97-105, 2014.

[34] W. Jia, Y. Luo, J. Yu et al., "Effects of high-repetition-rate femtosecond laser micromachining on the physical and chemical properties of polylactide (PLA)," Optics Express, vol. 23, no. 21, pp. 26932-26939, 2015.

[35] Z. Gui, Y. Xu, S. Cheng, Y. Gao, and C. Lu, "Preparation and characterization of polylactide/poly(polyethylene glycolco-citric acid) blends," Polymer Bulletin, vol. 70, no. 1, pp. 325$342,2013$.

[36] Z. Qiu and H. Pan, "Preparation, crystallization and hydrolytic degradation of biodegradable poly(l-lactide)/polyhedral oligomeric silsesquioxanes nanocomposite," Composites Science and Technology, vol. 70, no. 7, pp. 1089-1094, 2010.

[37] W.-W. Wang, C.-Z. Man, C.-M. Zhang, L. Jiang, Y. Dan, and T.-P. Nguyen, "Stability of poly(l-lactide)/TiO2 nanocomposite thin films under UV irradiation at $254 \mathrm{~nm}$," Polymer Degradation and Stability, vol. 98, no. 4, pp. 885-893, 2013.

[38] E. W. Fischer, H. J. Sterzel, and G. Wegner, "Investigation of the structure of solution grown crystals of lactide copolymers by means of chemical reactions," Kolloid-Zeitschrift \& Zeitschrift für Polymere, vol. 251, no. 11, pp. 980-990, 1973. 

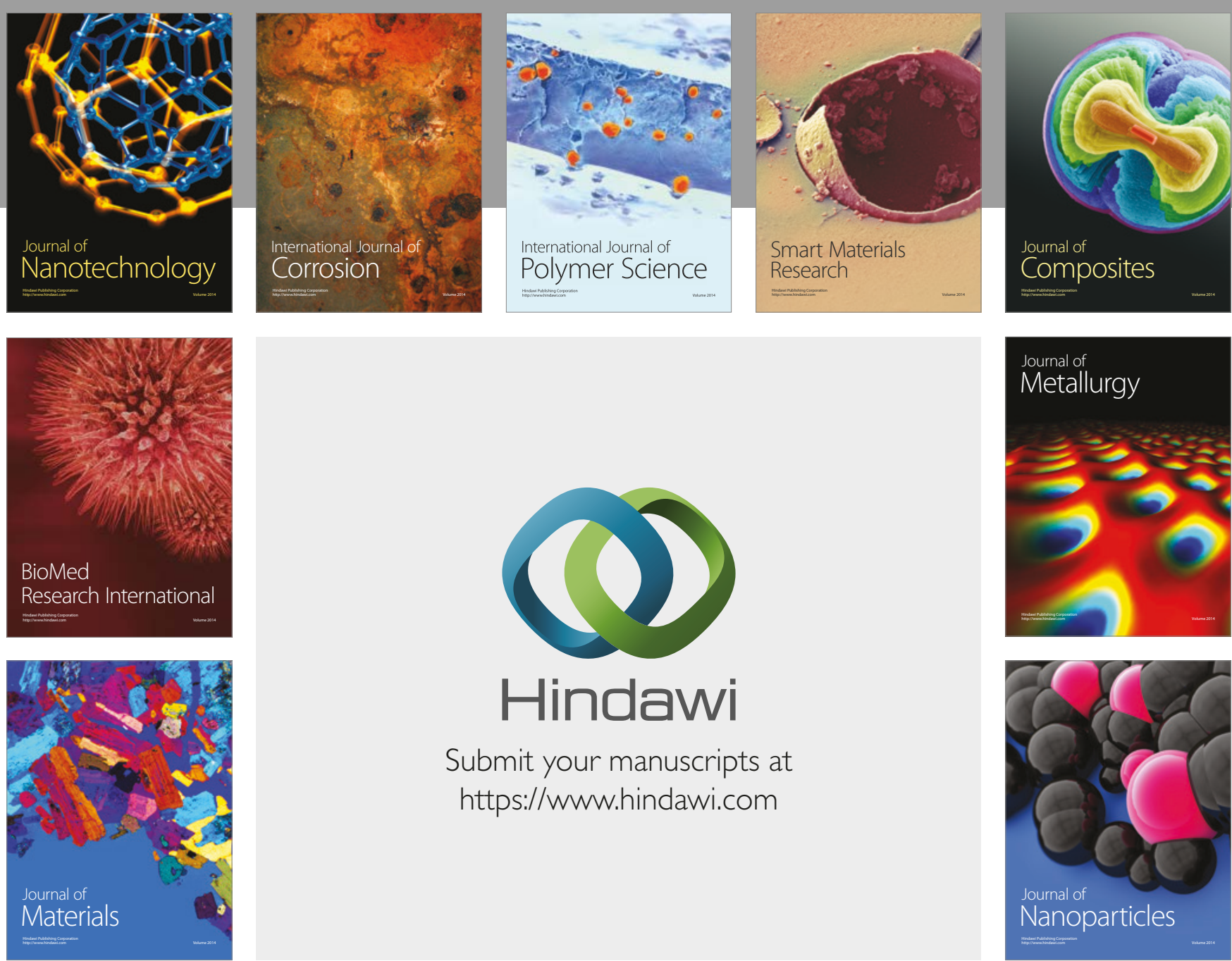

\section{Hindawi}

Submit your manuscripts at

https://www.hindawi.com
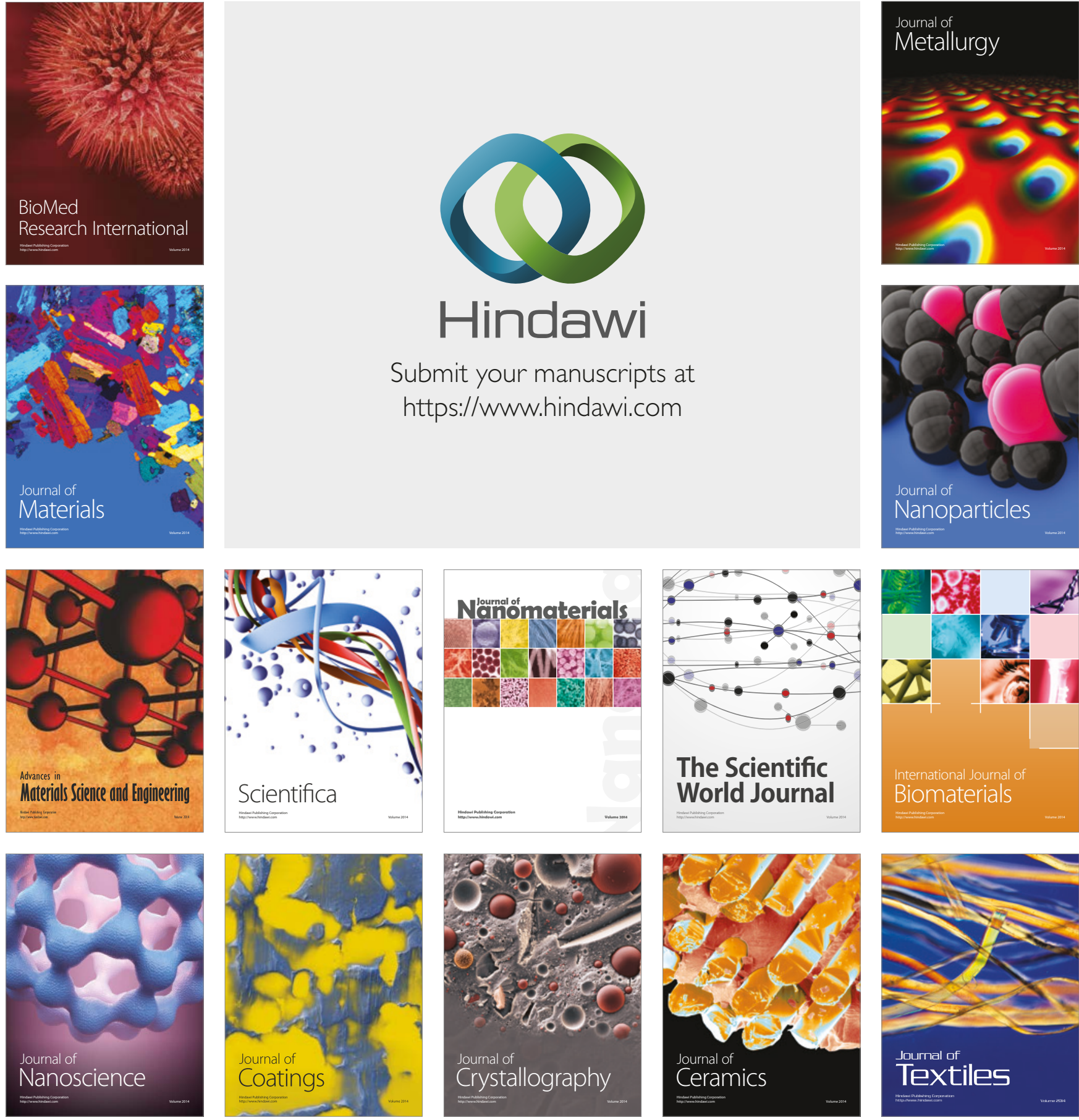

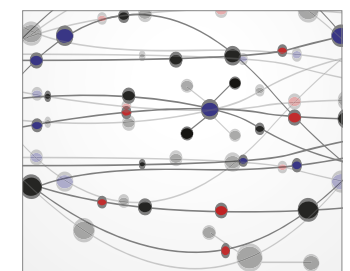

The Scientific World Journal
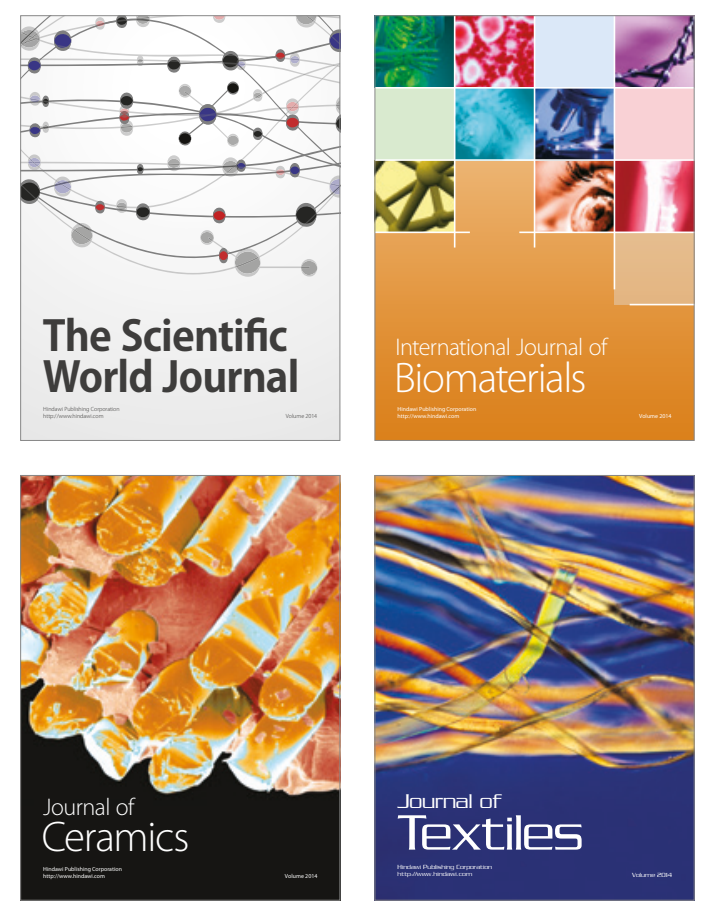